\title{
O crescimento brasileiro é sustentável?
}

Adalmir Marquetti*

RESUMO - O presente texto discute as condições necessárias para a continuidade da retomada do crescimento nos próximos anos. Aponta-se que há possibilidades da economia brasileira passar por uma nova etapa de crescimento sustentável, com taxas médias de expansão do PIB superiores a 4\% ao ano nos ciclos de negócios, se a taxa de investimento atingir patamares superiores a $20 \%$ ao ano.

Palavras-chave: Crescimento econômico. Economia brasileira. Acumulação de capital.

\section{INTRODUÇÃO}

Para 2010, é próxima de 6\% a expectativa de crescimento da economia brasileira. Caso se confirme, o PIB terá expandido a 4\% e o PIB per capita a 2,8\% ao ano entre 2004 e 2010, apesar da crise financeira internacional que atingiu o país a partir do quarto trimestre de 2008. O desempenho é praticamente o dobro do observado entre 1980 e 2003, quando o Brasil cresceu a uma taxa média de 2,2\% ao ano. Passamos do grupo de países com elevadas taxas de crescimento no período da Idade Dourada do desenvolvimento capitalista (19501973), quando a economia brasileira se expandiu a uma taxa anual de 7\%, para o grupo que possuía taxas reduzidas de crescimento no capitalismo neoliberal.

Em que medida o crescimento verificado a partir de 2003 representa a ruptura com o desempenho prevalecente nas décadas perdidas e quais são as condições necessárias para a continuidade da retomada do crescimento são os temas abordados na presente nota. Definese o crescimento sustentável pela obtenção de taxas médias de expansão do PIB superiores a 4\% ao ano nos ciclos de negócios. Portanto, há indícios de que a economia brasileira está iniciando uma nova etapa de crescimento sustentável.

\section{CRESCIMENTO ECONÔMICO E ACUMULAÇÃO DE CAPITAL FIXO}

O principal determinante do crescimento econômico brasileiro ao longo dos ciclos econômicos tem sido a acumulação de capital fixo. Durante o período 1953-1980, a taxa

\footnotetext{
* Departamento de Economia, Pontifícia Universidade Católica do Rio Grande do Sul - PUC-RS. Endereço eletrônico: aam@pucrs.br.
} 
média de acumulação de capital foi de 14,1\%, enquanto no período 1980-2003 ela foi de 9,3\% ao ano, uma queda próxima a 5\% ao ano. Portanto, para cada $1 \%$ de queda na taxa de acumulação houve uma redução de 1\% na taxa de crescimento do PIB. Assim, para o país crescer de modo sustentável entre $4 \%$ a $5 \%$ ao ano é necessário que a taxa de acumulação do capital fixo aumente $2 \%$ em relação ao período 1980-2003, o que, para a presente produtividade do capital e distribuição funcional da renda, requer uma taxa de investimento próxima de $21 \%$.

O gráfico abaixo apresenta a taxa de investimento na economia brasileira. Os dados da formação bruta de capital fixo e do PIB trimestral a preços correntes foram acumulados para quatro trimestres para, então calcular a razão entre as variáveis. A maior taxa de investimento foi de 21,5\% em 1994, no começo do Plano Real; a menor foi de 15,3\% em 2003, quando passou a aumentar, atingindo 18,8\% no final de 2008. Em razão da crise financeira, ela caiu para 16,9\% em 2009.

GRÁFICO 1: TAXA DE INVESTIMENTO NA ECONOMIA BRASILEIRA: 1991-IV / 2009-IV

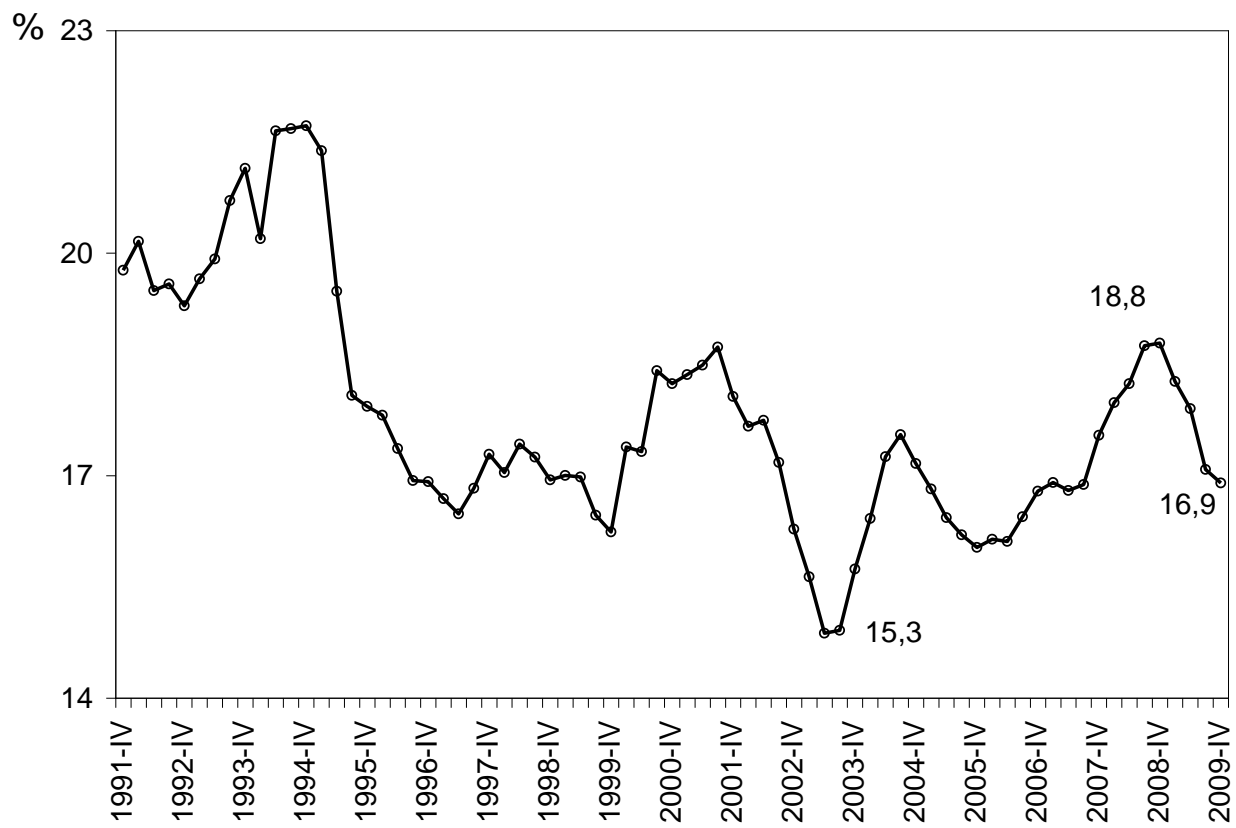

FONTE: dos dados brutos, IBGE (2009).

Importante ressaltar que o crescimento médio anual entre 2004 e 2010 com a taxa de investimento menor do que $20 \%$ foi possível devido ao aumento da utilização da capacidade instalada. A figura dois mostra a utilização da capacidade na indústria brasileira para os meses de janeiro entre 1997 e 2010. Houve um aumento na utilização da capacidade instalada após 2004 que atingiu o máximo em 2008, seguida de uma forte queda em decorrência da crise. 
Em janeiro de 2010, ela se aproximou do nível de 2006; a crise financeira internacional no caso brasileiro tomou a forma de um V.

A taxa de investimentos atingirá os valores necessários para o país crescer de modo sustentável a partir de 2011 se determinadas condições forem verificadas. A primeira condição é a perspectiva de aumento da demanda com a continuidade da recuperação do nível de utilização da capacidade instalada. Em decorrência da crise, as empresas cortaram seus planos de investimento em 2009, os mesmos serão implementados com a continuidade da recuperação econômica e o consequente o aumento da demanda.

GRÁFICO 2: UTILIZAÇÃO DA CAPACIDADE INSTALADA NA INDÚSTRIA NO MÊS DE JANEIRO, 1998-2010

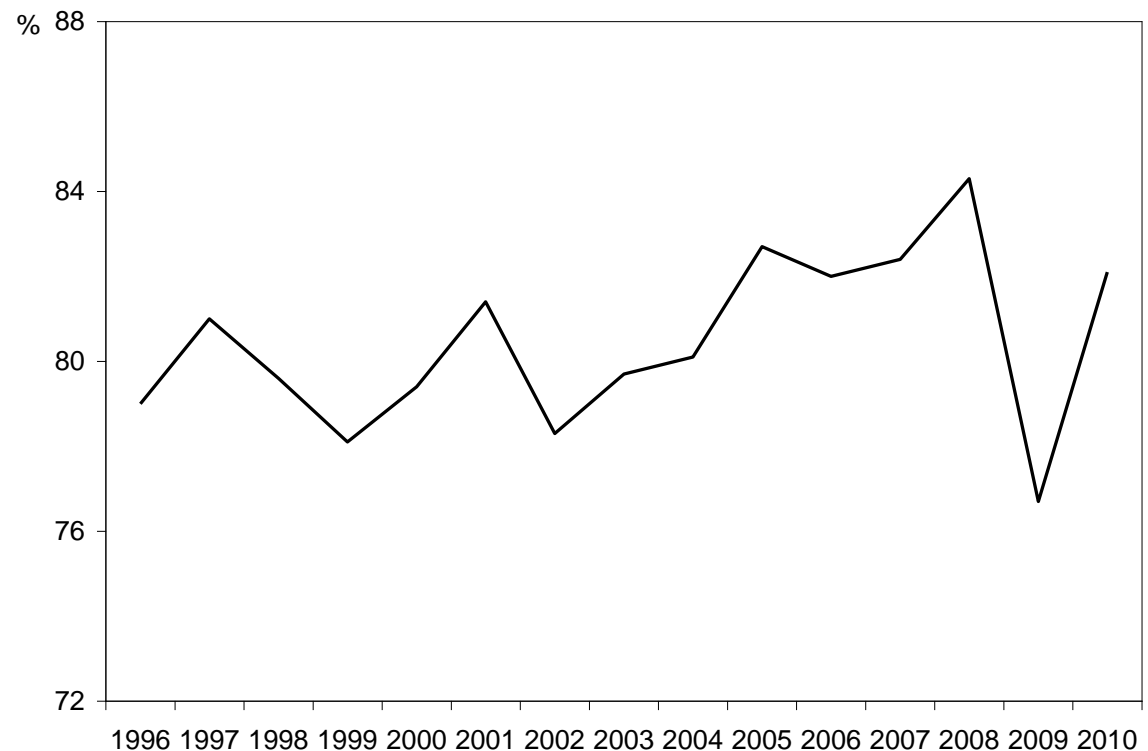

FONTE: dos dados brutos, Ipeadata (2010).

A segunda condição é a mudança na condução da política monetária no que tange ao controle da inflação, com alterações no regime de metas de inflação. A política monetária deve ser empregada com objetivos que vão além do controle da inflação. Foi com a crise econômica e a possibilidade de uma forte redução do nível de produção e aumento do desemprego que a taxa de juros básica caiu abaixo de dois dígitos. Ficou evidente que é possível associar outros objetivos à política monetária, além do combate à inflação.

A crise também reduziu o poder político do Banco Central; há espaço para modificar o regime de metas de inflação, em particular, elevar a meta, o que possibilitaria a continuidade da redução da SELIC. Contudo, com a retomada do crescimento, já há vozes no mercado financeiro que defendem o aumento da SELIC.

A queda na taxa de juros teria reflexos na política fiscal e no custo de rolagem da dívida pública. A redução das taxas reais e nominais de juros possibilitaria uma importante 
mudança na composição dos gastos públicos: ocorreria queda nos gastos com o pagamento de juros e a possibilidade do aumento dos investimentos e gastos públicos. Haveria a redução do superávit primário necessário para manter a relação dívida/PIB constante e, mesmo, a possibilidade de zerar o déficit nominal com uma combinação de menor taxa de juros e maior crescimento econômico.

Outro efeito importante é sobre a taxa de câmbio. A diferença entre a taxa de juros dos títulos da dívida pública brasileira em relação às taxas internacionais é um fator importante de atração de recursos financeiros e, portanto, de apreciação do real. A taxa de câmbio sobrevalorizada produz dois efeitos perversos sobre o crescimento econômico. Primeiro, ela aumenta o déficit em conta corrente e a necessidade de atrair poupança externa através da conta de capital, o que resulta no aumento do passivo externo. Segundo, ela reduz a competitividade da indústria, o que acelera o processo de desindustrialização no médio e longo prazo. Como a experiência chinesa bem demonstra, o crescimento a taxas elevadas por longos períodos tem maior probabilidade de ocorrer com uma taxa de câmbio depreciada.

A terceira condição é justamente reduzir o déficit da conta corrente. É muito improvável que o Brasil cresça de modo sustentável com déficits persistentes na conta corrente na ordem de 50 US\$ bilhões por ano. Segundo o Boletim Focus, essa é a expectativa do "mercado" para o triênio 2010-2012, em 2009 e 2008 o déficit foi da ordem de 25 US\$ bilhões.

Portanto, a política macroeconômica de curto prazo deve combinar uma menor taxa de juros, maior desvalorização cambial e, possivelmente, uma taxa de inflação entre um a dois pontos percentuais maiores do que a vigente.

\section{CRESCIMENTO ECONÔMICO, DEMOCRACIA E PLANEJAMENTO}

A quarta condição, e a mais fundamental, é a decisão do governo brasileiro em adotar um plano estratégico voltado para o desenvolvimento econômico. O Plano de Aceleração do Crescimento (PAC) representa um passo importante nessa direção e tem como um dos principais méritos a retomada do papel do estado no que tange ao planejamento econômico e coordenação dos investimentos públicos e privados. O PAC tem como ponto central a retomada dos investimentos públicos e do investimento das empresas estatais.

Os investimentos realizados hoje não somente moldam a estrutura produtiva, como também tem papel importante na definição do tipo de emprego e na distribuição da renda vigente no futuro. Assim, o plano de desenvolvimento estratégico deve apontar claramente 
que tipo de país pretendemos ser no futuro. O crescimento sustentável requer maior investimento e a sociedade brasileira, em particular os setores sociais tradicionalmente excluídos do debate político, devem ter papel importante na elaboração do plano de desenvolvimento e, portanto, na definição dos investimentos a serem realizados. Espelhando-se na Constituição de 1988, a elaboração e a execução do plano devem combinar elementos da democracia social com a democracia participativa para que o crescimento econômico beneficie a população pobre do país. Uma das razões do insucesso do II Plano Nacional de Desenvolvimento foi justamente seu caráter autoritário e antidemocrático.

A razão para o Brasil ter um plano de desenvolvimento é muito simples: o mercado, por suas próprias forças realiza diversas tarefas, mas não é capaz de propiciar crescimento sustentável e distribuição de riqueza e renda.

\section{RUPTURA COM PERÍODO DE BAIXO CRESCIMENTO}

Para o Brasil manter taxas médias de crescimento superiores a $4 \%$ ao ano é necessário alcançar uma relação investimento/PIB de 21\%. No terceiro trimestre de 2008, a taxa de investimento foi superior a $20 \%$, mas caiu rapidamente com efeitos da crise econômica no país. Entre 2004 e 2010, o país aumentou sua taxa de crescimento para níveis muito próximos do crescimento sustentável, apesar da taxa de investimento estar abaixo do requerido. Isso foi possível devido a condições internacionais muito favoráveis, as quais são improváveis de se repetirem no futuro imediato, e a utilização da capacidade ociosa.

Foi em um segundo momento que o governo adotou o PAC, quando rompeu com muitos dos elementos do neoliberalismo. O modelo econômico neoliberal não é voltado ao investimento produtivo e, portanto, como bem demonstra a experiência brasileira nos anos 90, resulta em baixo crescimento. A retomada articulada dos investimentos por parte do estado e das empresas públicas é condição fundamental para obter uma taxa de investimento da ordem de $21 \%$ ao ano. As empresas privadas ao invés de reduzirem seus investimentos, como predizem a teoria neoclássica, aumentam seus investimentos frente à expectativa de maior lucratividade que decorrem da redução do custo de produção devido a melhora na infraestrutura do país.

É necessária a continuidade e o aprimoramento do plano de desenvolvimento, bem como a adequação da política econômica de curto prazo para viabilizar a implementação do mesmo. Segundo notícias, o Governo Lula deverá anunciar algumas das medidas do PAC II em breve. Assim, algumas das condições chaves para obter uma taxa de investimento da 
ordem de $21 \%$ ao ano estão sendo cumpridas, apesar dos efeitos da política monetária de caráter neoliberal sobre os gastos públicos e a taxa de câmbio. Há possibilidades de que o espetáculo do crescimento econômico sustentável ocorra nos próximos anos. 